\title{
Mitochondrial oxidative DNA damage and exposure to particulate air pollution in mother-newborn pairs
}

Lotte Grevendonk', Bram G. Janssen², Charlotte Vanpoucke ${ }^{3}$, Wouter Lefebvre ${ }^{4}$, Mirjam Hoxha', Valentina Bollati ${ }^{1}$ and Tim S. Nawrot ${ }^{2,5^{*}}$

\begin{abstract}
Background: Studies emphasize the importance of particulate matter (PM) in the formation of reactive oxygen species and inflammation. We hypothesized that PM exposure during different time windows in pregnancy influences mitochondrial 8-hydroxy-2'-deoxyguanosine (8-OHdG) levels, which is an established biomarker for oxidative stress, in both maternal and foetal blood.

Methods: We investigated maternal $(n=224)$ and cord blood $(n=293)$ from mother-newborn pairs that were enrolled in the ENVIRONAGE birth cohort. We determined mitochondrial 8-OHdG by quantitative polymerase chain reaction (qPCR). Multivariable regression models were used to assess the association between mitochondrial 8-OHdG with $\mathrm{PM}_{10}$ and $\mathrm{PM}_{2.5}$ exposure over various time windows during pregnancy.

Results: In multivariable analysis, $\mathrm{PM}_{10}$ exposure during the entire pregnancy was positively associated with levels of mitochondrial 8-OHdG in maternal blood. For an IQR increment in $\mathrm{PM}_{10}$ exposure an increase of $18.3 \%$ (95\% confidence interval (Cl): 5.6 to $33.4 \%, p=0.004)$ in $8-\mathrm{OHdG}$ was observed. $\mathrm{PM}_{10}$ exposure during the last trimester of pregnancy was positively associated with levels of 8-OHdG (28.1, $95 \% \mathrm{Cl}: 8.6$ to $51.2 \%, p=0.004$, for an IQR increment in $\mathrm{PM}_{10}$ ). In a similar way, $\mathrm{PM}_{2.5}$ exposure was significantly associated with an increase of mitochondrial 8-OHdG levels in maternal blood during the entire pregnancy $\left(13.9,95 \% \mathrm{Cl}: 0.4\right.$ to $29.4 \%, p=0.04$ for an IQR increment in $\mathrm{PM}_{2.5}$ exposure) and third trimester of pregnancy (28.1, $95 \%$ Cl: 3.6 to $58.4 \%, p=0.02$ for an IQR increment in $\mathrm{PM}_{2.5}$ exposure). In umbilical cord blood, 8-OHdG levels were significantly associated with $\mathrm{PM}_{10}$ exposure during first and second trimester of pregnancy with respectively an increase of $23.0 \%$ (95\% Cl: 5.9 to $42.8 \%, p=0.007$ ) and $16.6 \%$ (95 \% Cl: 1.8 to $33.5 \%, p=0.03$ ) for an IQR increment in $\mathrm{PM}_{10}$ exposure.

Conclusions: We found PM-associated increased mitochondrial oxidative DNA damage during pregnancy in both mothers and their newborns. Accordingly, our study showed that particulate air pollution exposure in early life plays a role in increasing systemic oxidative stress, at the level of the mitochondria, both in mother and foetus.
\end{abstract}

Keywords: 8-OHdG, Foetal development, Mitochondrial function, Oxidative damage, Particulate matter

\footnotetext{
* Correspondence: tim.nawrot@uhasselt.be

${ }^{2}$ Centre for Environmental Sciences, Hasselt University, Hasselt, Belgium

${ }^{5}$ Department of Public Health \& Primary Care, Occupational and

Environmental Medicine, Leuven University, Leuven, Belgium

Full list of author information is available at the end of the article
} 


\section{Background}

Particulate matter (PM) air pollution exposure is a known risk factor for the induction of inflammatory and oxidative stress responses [1-4], especially during the pregnancy period when increased levels of oxidative stress can be expected [5]. Mitochondria are the main intracellular source and target of reactive oxygen species (ROS) that are continually generated as by-products of mitochondrial respiration in the electron transport chain [6].

Among the different types of ROS-induced DNA damage, the oxidation of guanine and consequently the formation of 8-hydroxy-2'-deoxyguanosine (8-OHdG) is the most common one [7]. Oxidative DNA damage can be repaired by means of 8-OHdG removal from the nuclear, but also the mitochondrial genome, representing a steady-state level of oxidative stress within a cell [8]. Contrary to human nuclear DNA (nDNA), mitochondrial DNA (mtDNA) lacks the protective chromatin structure, histones, and introns. Moreover, the mtDNA repair mechanisms work less efficiently resulting in a 5 to 15 times higher mutation rate compared with nDNA $[6,9]$. High and continuous exposure to PM-induced ROS in mitochondria are likely to cause oxidative mtDNA damage as reflected by increased amounts of mitochondrial 8OHdG levels. Accumulation of mitochondrial 8-OHdG levels, and subsequent mtDNA mutations, are reported to be a risk factor for many diseases including diabetes [10] and cancer [11]. The strict maternal inheritance of mtDNA means that mtDNA mutations arising in the embryonic period can be dispersed throughout the body of the fetus. Several studies demonstrated an association between nuclear 8-OHdG levels and PM exposure [12-16] but whether exposure to PM during gestation influences mitochondrial 8-OHdG both in mothers and newborns is not known.

In the framework of the ENVIRONAGE birth cohort (ENVIRonmental influence ON early AGEing), we hypothesized that mitochondrial oxidative DNA damage, as exemplified by mitochondrial $8-\mathrm{OHdG}$, is associated with airborne PM exposure during gestation.

\section{Methods}

\section{Study population and data collection}

We recruited mother-newborn pairs (only singletons) in the East-Limburg Hospital in Genk, Belgium who are part of the ongoing birth cohort "ENVIRONAGE". The current study comprises 293 cord blood samples collected immediately after delivery and 224 maternal blood samples collected at the maternal unit 24-48 h after delivery. The participation rate of eligible mothers in the birth cohort (mothers able to fill out a Dutch language questionnaire) was $61 \%$ and enrolment was spread equally over all seasons of the year. Participating mothers had to complete a study questionnaire to provide detailed information on age, maternal education, occupation, ethnicity, smoking status, place of residence, pre-gestational body mass index (BMI), parity, and newborn's ethnicity. Past-smokers were defined as those who had quit before pregnancy and smokers as having smoked before and during pregnancy. Women reported whether they were exposed to secondhand smoke at their home address. Maternal education was coded as low (no diploma or primary school), middle (high school), or high (college or university degree). We asked the mothers whether they consumed alcohol during pregnancy. Perinatal parameters such as newborn's gender, birth date, birth weight and length, gestational age, Apgar score, and ultrasonographic data were collected after birth. The present study was conducted according to the principles outlined in the Helsinki Declaration (World Medical Association 2008) [17] for investigation of human subjects. Written informed consent was obtained from all participating mothers when they arrived at the hospital for delivery and was in accordance with procedures approved by the Ethical Committee of Hasselt University and EastLimburg Hospital in Genk.

\section{Exposure assessment}

For each mother's residential address, we interpolated the regional background levels of $\mathrm{PM}_{2.5}$ and $\mathrm{PM}_{10}\left(\mu \mathrm{g} / \mathrm{m}^{3}\right)$ using a spatial temporal interpolation method (Krigin) [18] that uses pollution data collected in the official fixed site monitoring and land cover data obtained from satellite images (CORINE land cover data set) in combination with a dispersion model $[19,20]$ ). This model chain provides daily $\mathrm{PM}_{2.5}$ and $\mathrm{PM}_{10}$ values using data both from the Belgian telemetric air quality network from point sources and line sources which are then interpolated to a high-resolution receptor grid. The date of conception was estimated based on ultrasound data. We explored potential critical windows of exposures during pregnancy using daily mean $\mathrm{PM}_{2.5}$ and $\mathrm{PM}_{10}$ concentrations averaged over various periods. Exposure windows of interest included each of the three trimesters of pregnancy, with trimesters being defined as: 1-13 weeks (first trimester), 14-26 weeks (second trimester), and 27 weeks to delivery (third trimester). The exposure during the entire pregnancy was calculated as the mean of all pregnancy days. Address changes during the period of pregnancy were taken into account when calculating the exposure windows $(n=16 ; 7.1 \%)$.

\section{Sample collection and processing}

Maternal and venous umbilical cord blood was collected after delivery in plastic BD Vacutainer ${ }^{\bullet}$ Plus Plastic K2EDTA Tubes (BD, Franklin Lakes, NJ, USA). Samples were centrifuged (3200 rpm for $15 \mathrm{~min}$ ) to retrieve buffy coats and instantly frozen, first at $-20{ }^{\circ} \mathrm{C}$ and later at $-80{ }^{\circ} \mathrm{C}$. Genomic DNA was isolated from buffy coat of maternal blood $(n=224)$ and umbilical 
cord blood $(n=293)$ using the QIAamp ${ }^{\circ}$ DNA minikit (Qiagen, Inc., Venlo, the Netherlands) and stored at $-80{ }^{\circ} \mathrm{C}$ until further use.

\section{Determination of the 8-OHdG levels in mitochondria}

Mitochondrial 8-OHdG was measured using quantitative real-time polymerase chain reaction (qPCR) as previously described in detail $[11,21]$. Briefly, $4 \mu \mathrm{l}$ of DNA sample $(6.25 \mathrm{ng} / \mu \mathrm{l})$ was treated with $11 \mu \mathrm{l}$ treatment mix containing RNase free water $(8.7 \mu \mathrm{l} /$ reaction $)$, buffer NE $10 \times$ $(1.5 \mu \mathrm{l} /$ reaction $)$, BSA $100 \times(0.15 \mu \mathrm{l} /$ reaction $)$, and the enzyme human oxoguanine glycosylase 1 (hOGG1) or RNase free water $(0.625 \mu \mathrm{l} /$ reaction) for the treatment mix and non-treatment mix respectively. After an incubation of $1 \mathrm{~h}$ at $37^{\circ} \mathrm{C}$, samples were diluted 1:4 in RNase free water and a fragment of mtDNA (MTF3212/R3319) was amplified by qPCR using a master mix consisting of $\mathrm{TaqMan}^{\circ}$ Fast Advanced Master Mix (Applied Biosystems; $5 \mu \mathrm{L} /$ reaction), forward $(0.5 \mu \mathrm{L} /$ reaction $)$ and reverse $(0.5 \mu \mathrm{L} /$ reaction $)$ primers (F:5'-CACCCAAGAACAGGGTTTGT-3' and R:5' -TTAACAACATACCCATGGCCA-3'), and $4 \mu \mathrm{l}$ of treated or non-treated DNA. Samples were run in triplicate in a MicroAmp ${ }^{\circ}$ Fast Optical 384-Well Reaction Plate compatible with the 7900HT Fast Real-Time PCR System (Applied Biosystems, Foster City, CA, USA). Each plate contained two non-template controls and four interrun calibrators to account for plate variability. The thermal cycling profile started with $10 \mathrm{~s}$ at $95^{\circ} \mathrm{C}$, followed by 35 cycles of $15 \mathrm{~s}$ at $95^{\circ} \mathrm{C}$ plus $1 \mathrm{~min}$ at $60^{\circ} \mathrm{C}$. qBase software (Biogazelle, Zwijnaarde, $\mathrm{BE}$ ) was used to automatically average triplicate measurements that passed quality control and to correct for run-to-run differences [22]. Afterwards, differences in amplification efficiency between non-treated and treated DNA $(\Delta \mathrm{Ct})$ were calculated.

\section{mtDNA content analysis}

mtDNA content was measured using a qPCR assay by determining the ratio of two mitochondrial gene copy numbers (MTF3212/R3319 and MT-ND1) to two singlecopy nuclear control genes (RPLPO and ACTB) as previously described [17] but with small modification. Isolated genomic DNA (12.5 ng) was added to $7.5 \mu \mathrm{l}$ mastermix consisting of Fast $\mathrm{SYBR}^{\circ}$ Green I dye $2 \times(5 \mu \mathrm{l} /$ reaction), forward and reverse primer (each $0.3 \mu \mathrm{l} /$ reaction) and RNase free water $(1.9 \mu \mathrm{l} /$ reaction), for a final volume of $10 \mu \mathrm{l}$ per reaction. Primer sequences (Additional file 1: Table S1) were diluted to a final concentration of $300 \mathrm{nM}$ in the master mix. Samples were run in triplicate in 384well format. Real-time PCR was performed using the 7900HT Fast Real-Time PCR System (Applied Biosystems, Foster City, CA, USA) with following thermal cycling profile: $20 \mathrm{~s}$ at $95^{\circ} \mathrm{C}$, followed by 40 cycles of $1 \mathrm{~s}$ at $95^{\circ} \mathrm{C}$ and $20 \mathrm{~s}$ at $60{ }^{\circ} \mathrm{C}$, ending with melting curve analysis $(15 \mathrm{~s}$ at $95{ }^{\circ} \mathrm{C}, 15 \mathrm{~s}$ at $60{ }^{\circ} \mathrm{C}, 15 \mathrm{~s}$ at $\left.95{ }^{\circ} \mathrm{C}\right)$. qBase software
(Biogazelle, Zwijnaarde, BE) was used to normalize data and correct for run-to-run differences [22].

\section{Statistical analysis}

For database management and statistical analysis, we used the SAS software program (version 9.2; SAS Institute Inc., Cary, NC, USA). mtDNA 8-OHdG levels and mtDNA content data were $\log _{10}$-transformed to improve normality. Pearson correlation coefficients and multiple linear regression were used to assess the correlation and association between $\mathrm{PM}_{2.5}$ or $\mathrm{PM}_{10}$ exposure with mtDNA 8-OHdG in maternal blood and cord blood and to assess the correlation and association between mtDNA 8-OHdG and mtDNA content in maternal and cord blood. The models for maternal blood were controlled for a priori chosen variables including maternal age, gestational age, smoking status, maternal education, alcohol consumption during pregnancy, and season at conception, while the models for cord blood additionally were adjusted for gender and date of delivery. $\beta$ regression coefficients represent a relative percentage change for an increment between the interquartile range (IQR; 25th-75th percentile) in the independent variable.

In a sensitivity analysis, we assessed the association between $\mathrm{PM}_{2.5}$ or $\mathrm{PM}_{10}$ exposure during pregnancy and 8-OHdG levels in maternal and cord blood while excluding women who smoked during pregnancy. We explored whether assisted reproductive technologies may alter the association between PM exposure and cord or maternal 8-OHdG levels. Lastly, we investigated whether PM exposure or 8-OHdG levels were associated with pregnancy outcomes such as birth weight using linear regression models and small for gestational age using logistic regression models. The Shapiro-Wilk statistic and Q-Q plots of the residuals were used to test the assumptions of all linear models.

\section{Results}

Lifestyle factors were collected by means of a self-reported questionnaire and are displayed in Table 1. In this study, 293 pregnant women were included with an average (SD) age of 29 (4.8) years (range: 17-44 years). Mean pregestational BMI of participating mothers averaged 24.2 $(4.7) \mathrm{kg} / \mathrm{m}^{2}$. Most women $(n=195,66.5 \%)$ never smoked cigarettes whereas 47 mothers $(16.1 \%)$ reported to have smoked during pregnancy and 51 women (17.4 \%) reported to have smoked before pregnancy. Most mothers $(n=235,80.2 \%)$ did not consume alcohol during their pregnancy, while $19.8 \%(n=58)$ reported to have consumed alcohol occasionally. Most women (90.4\%) had a spontaneous pregnancy without the use of artificial reproductive technology. The newborns, among them 140 males (47.8\%), had a mean gestational age of $39.2(1.2)$ weeks. Table 2 displays the daily outdoor $\mathrm{PM}_{10}$ and $\mathrm{PM}_{2.5}$ 
Table 1 Characteristics of mother-newborn pairs $(n=293)$

\begin{tabular}{|c|c|}
\hline Maternal characteristics & $\begin{array}{l}\text { Mean } \pm \text { SD or range } \\
\text { and number (\%) }\end{array}$ \\
\hline Age, year & $29 \pm 4.8$ \\
\hline Pre-gestational BMl, kg/m² & $24.2 \pm 4.7$ \\
\hline Gestational age, weeks & $39.2 \pm 1.2$ \\
\hline \multicolumn{2}{|l|}{ Maternal education } \\
\hline Low & $39(13.3)$ \\
\hline Middle & $98(33.5)$ \\
\hline High & $156(53.2)$ \\
\hline \multicolumn{2}{|l|}{ Smoking } \\
\hline Never-smoker & $195(66.5)$ \\
\hline Past-smoker & $51(17.4)$ \\
\hline Smoker & $47(16.1)$ \\
\hline \multicolumn{2}{|l|}{ Second-hand smoke exposure ${ }^{a}$} \\
\hline Not exposed & 260 \\
\hline Non-smoker, exposed & 14 \\
\hline Smoker, exposed & 10 \\
\hline \multicolumn{2}{|l|}{ Alcohol } \\
\hline No & $235(80.2)$ \\
\hline Occasionally & $58(19.8)$ \\
\hline \multicolumn{2}{|l|}{ Assisted reproductive technology } \\
\hline Spontaneous & $265(90.4)$ \\
\hline Hormonal & $7(2.4)$ \\
\hline In vitro fertilization & $12(4.1)$ \\
\hline Intracytoplasmic sperm injection & $4(1.4)$ \\
\hline Artificial insemination & $5(1.7)$ \\
\hline \multicolumn{2}{|l|}{ Newborn's gender } \\
\hline Male & $140(47.8)$ \\
\hline Female & $153(52.2)$ \\
\hline \multicolumn{2}{|l|}{ Season at delivery } \\
\hline Fall & $73(24.9)$ \\
\hline Winter & $67(22.9)$ \\
\hline Spring & $94(32.1)$ \\
\hline Summer & $59(20.1)$ \\
\hline
\end{tabular}

${ }^{\text {aData available for } 284 \text { individuals }}$

exposure levels averaged for the entire pregnancy and each of the three trimesters of pregnancy. Median (25th-75th percentile) trimester-specific $\mathrm{PM}_{10}$ exposure was 19.2 (16.6-23.8) $\mu \mathrm{g} / \mathrm{m}^{3}$ for the first trimester, $21(17.4-23.8)$ $\mu \mathrm{g} / \mathrm{m}^{3}$ for the second trimester, $22.2(17.3-26.1) \mu \mathrm{g} / \mathrm{m}^{3}$ for the third trimester, and 21.4 $(19.8-22.8) \mu \mathrm{g} / \mathrm{m}^{3}$ for the entire pregnancy.

Mitochondrial 8-OHdG levels in maternal blood were positively correlated with $\mathrm{PM}_{10}$ and $\mathrm{PM}_{2.5}$ exposure during the entire pregnancy. An IQR increment in $\mathrm{PM}_{10}$ exposure was associated with an increase in maternal mitochondrial 8-OHdG levels of $15.7 \quad \% \quad \begin{array}{llll}95 & \%\end{array}$
Table 2 Exposure characteristics during pregnancy $(n=293)$

\begin{tabular}{lcccccc}
\hline Variable & Min & $25 \%(\mathrm{Q} 1)$ & Median & $75 \%(\mathrm{Q} 3)$ & Max & $\mathrm{IQR}$ \\
\hline $\mathrm{PM}_{10}, \mathrm{\mu g} / \mathrm{m}^{3}$ & & & & & & \\
1st trimester & 12.3 & 16.6 & 19.2 & 23.8 & 37.6 & 7.2 \\
2nd trimester & 11.1 & 17.4 & 21.0 & 23.8 & 34.6 & 6.4 \\
3rd trimester & 11.5 & 17.3 & 22.2 & 26.1 & 37.3 & 8.8 \\
Entire pregnancy & 15.3 & 19.8 & 21.4 & 22.8 & 27.3 & 3.0 \\
$\mathrm{PM}_{2.5}, \mathrm{\mu g} / \mathrm{m}^{3}$ & & & & & & \\
1st trimester & 7.8 & 11.8 & 14.3 & 19.9 & 29.6 & 8.1 \\
2nd trimester & 7.9 & 12.1 & 16.2 & 19.9 & 28.6 & 7.8 \\
3rd trimester & 7.9 & 11.9 & 17.1 & 22.0 & 31.4 & 10.1 \\
Entire pregnancy & 11.3 & 15.1 & 16.6 & 18.0 & 22.0 & 2.9 \\
\hline
\end{tabular}

confidence interval $(\mathrm{CI}): 4.8$ to $27.6 \%, p=0.004)$. For an IQR increment in $\mathrm{PM}_{2.5}$ exposure a positive trend in 8OHdG levels was observed $(10.1 \%, 95 \% \mathrm{CI}:-0.2$ to $21.3 \%, p=0.05)$. The association remained significant after adjustment for maternal age, gestational age, smoking status, maternal education, alcohol consumption and season at conception (Table 3). An IQR increment in $\mathrm{PM}_{10}$ and $\mathrm{PM}_{2.5}$ during the entire pregnancy was associated with a change in maternal 8-OHdG of $+18.3 \%$ (95\% CI: 5.6 to $32.4 \%, p=0.004)$ and $+13.9 \%$ (95\% CI: 0.4 to $29.4 \%, p=0.04$ ) respectively. Considering the exposures during the trimesters separately, a positive association was observed between 8-OHdG levels in maternal blood with $\mathrm{PM}_{10}$ and $\mathrm{PM}_{2.5}$ exposure during the third trimester of pregnancy $(+28.1 \%, 95 \%$ CI: 8.6 to $51.2 \%, p=0.004$ and $+28.1 \%, 95 \%$ CI: 3.6 to $58.4 \%$, $p=0.02$ for an IQR increment in $\mathrm{PM}_{10}$ and $\mathrm{PM}_{2.5}$ exposure respectively). Exposure to $\mathrm{PM}_{10}$ and $\mathrm{PM}_{2.5}$ during the first and second trimester of pregnancy was not significantly associated with maternal 8-OHdG levels, although a positive trend was observed $(p>0.14)$.

To investigate whether the effects we observed in maternal blood are passed through or translated to the foetus, we determined levels of 8-OHdG in cord blood of 293 newborns. After adjustment of the aforementioned variables plus newborns gender and delivery date, we did not observe a significant association between cord blood 8OHdG levels and $\mathrm{PM}_{10}$ or $\mathrm{PM}_{2.5}$ exposure during the entire pregnancy although a positive trend was observed $(p>0.11)$. However, considering the separate exposure windows, we observed a significant positive association between cord blood 8-OHdG and $\mathrm{PM}_{10}$ exposure during the first and second trimester of pregnancy (Table 4). An IQR increment in $\mathrm{PM}_{10}$ exposure was associated with a change in mitochondrial 8-OHdG levels of $+23.0 \%(95 \%$ CI: 5.9 to $42.8 \%, p=0.007$ and $+16.6 \%$ (95 \% CI: 1.8 to $33.5 \%, p=0.03)$ respectively. Exposure to $\mathrm{PM}_{2.5}$ during the first and second trimester of pregnancy was not significantly associated although a positive trend was shown 
Table 3 Estimated change of mitochondrial 8-OHdG in maternal blood associated with $\mathrm{PM}_{10}$ and PM 2.5 exposure during pregnancy $(n=224)$

\begin{tabular}{|c|c|c|c|c|c|c|}
\hline \multirow[b]{2}{*}{ Time window } & \multicolumn{3}{|l|}{$\mathrm{PM}_{10}^{\mathrm{a}}$} & \multicolumn{3}{|l|}{$\mathrm{PM}_{2.5}^{\mathrm{a}}$} \\
\hline & Percent change ${ }^{b}$ & $95 \% \mathrm{Cl}$ & $\overline{p \text {-Value }}$ & Percent change ${ }^{b}$ & $95 \% \mathrm{Cl}$ & $p$-Value \\
\hline Trimester $1(1-13 w)$ & 7.3 & $-7.1,23.9$ & 0.34 & 3.0 & $-13.6,22.7$ & 0.74 \\
\hline Trimester 2 (14-26w) & 12.4 & $-3.89,31.5$ & 0.14 & 13.0 & $-9.1,40.4$ & 0.27 \\
\hline Trimester3 (27w-delivery) & 28.1 & $8.6,51.2$ & 0.004 & 28.1 & $3.6,58.4$ & 0.02 \\
\hline Entire pregnancy & 18.3 & $5.6,32.4$ & 0.004 & 13.9 & $0.4,29.4$ & 0.04 \\
\hline
\end{tabular}

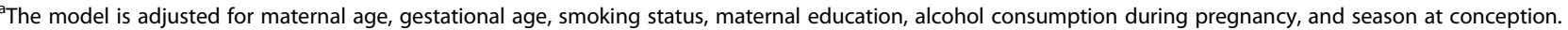
${ }^{b}$ The effect size is calculated as a relative percent change for an IQR increment in $\mathrm{PM}_{10}$ or $\mathrm{PM}_{25}$ exposure $\left(\mu \mathrm{g} / \mathrm{m}^{3}\right)$ at the mother's residence during the different time windows. The IQR for the different time windows for $\mathrm{PM}_{10}$ and $\mathrm{PM}_{2.5}$ is given in Table 2

(+15.8, $95 \% \mathrm{CI}:-2.4$ to $37.6 \%, p=0.09$ and $+12.1,95 \%$ CI: -5.7 to $33.1 \%, p=0.19)$. Contrary, exposure to $\mathrm{PM}_{10}$ and $\mathrm{PM}_{2.5}$ during the third trimester showed an inverse trend with 8-OHdG levels in cord blood, although this was not significant.

To explore the functional significance of the association between mitochondrial 8-OHdG with exposure to PM, we evaluated the association between mtDNA content, a measure of altered mitochondrial function, and 8-OHdG levels in maternal and cord blood. Pregnant mothers with high levels of 8-OHdG exhibited high levels of mtDNA content in their blood $(r=0.44, p<0.0001)$. Likewise, we observed a strong positive correlation between mitochondrial 8-OHdG and mtDNA content in cord blood $(\mathrm{r}=0.58$, $p<0.0001)$. These associations of $8-\mathrm{OHdG}$ and mtDNA content in cord blood and maternal blood remained significant after adjustment for the same covariates as in the maternal and cord blood model $(\beta=0.38$, $95 \%$ CI: 0.28 to $0.49, p<0.0001$ and $\beta=0.52,95 \% \mathrm{CI}$ : 0.43 to $0.61, p<0.0001$ respectively).

In a sensitivity analysis, we repeated all statistical analyses while excluding women who smoked during pregnancy $(n=47)$. This did not alter the reported associations between PM exposure and 8-OHdG in maternal and cord blood except that the associations between $\mathrm{PM}_{2.5}$ exposure and maternal 8-OHdG attenuated and did not reach significance anymore (Additional file 1: Table S2 and Table S3). Secondly, adjusting our main models with assisted reproductive technology did not change our findings (results not shown). Lastly, neither PM exposure nor 8-OHdG levels in cord and maternal blood were associated with birth weight or small for gestational age (Additional file 1: Table S4).

\section{Discussion}

Pregnancy is a state of increased physiological oxidative stress [5], and maternal exposure to particulate air pollution might exacerbate oxidative damage [1]. Our key finding was that maternal particulate air pollution exposure was positively associated with mitochondrial 8-OHdG, a marker of oxidative DNA damage, in maternal and cord blood. Accordingly, our research showed that particulate air pollution in early life plays a role in increasing systemic oxidative stress, at the level of the mitochondria, both in mother and foetus.

Most studies to date have analyzed excreted levels of 8OHdG in urine, reflecting nuclear DNA damage, instead of mitochondrial 8-OHdG levels like in our study. Consistent with our results, most of these studies observed a positive association between nuclear 8-OHdG levels in urine and PM exposure [14-16, 23-25] or tobacco smoke exposure [16, 26-29]. Also in human and in vitro blood lymphocytes, increases in nuclear $8-\mathrm{OHdG}$ levels have been associated with PM exposure [12,13]. To the best of our knowledge this is the first study investigating 8OHdG levels, specifically in the mitochondrial genome, in association with prenatal PM exposure. The advantage of measuring 8-OHdG in mtDNA compared with the

Table 4 Estimated change of mitochondrial 8-OHdG in cord blood associated with $\mathrm{PM}_{10}$ and $\mathrm{PM}_{2.5}$ exposure during pregnancy $(n=293)$

\begin{tabular}{|c|c|c|c|c|c|c|}
\hline \multirow[b]{2}{*}{ Time window } & \multicolumn{3}{|l|}{$\mathrm{PM}_{10}^{\mathrm{a}}$} & \multicolumn{3}{|l|}{$\mathrm{PM}_{2.5}^{\mathrm{a}}$} \\
\hline & Percent change $^{b}$ & $95 \% \mathrm{Cl}$ & $p$-Value & Percent change $^{b}$ & $95 \% \mathrm{Cl}$ & $p$-Value \\
\hline Trimester $1(1-13 w)$ & 23.0 & $5.9,42.8$ & 0.007 & 15.8 & $-2.4,37.6$ & 0.09 \\
\hline Trimester 2 (14-26w) & 16.6 & $1.8,33.5$ & 0.03 & 12.1 & $-5.7,33.1$ & 0.19 \\
\hline Trimester 3 ( $27 w$-delivery) & -13.4 & $-26.2,1.7$ & 0.08 & -14.9 & $-29.4,2.6$ & 0.09 \\
\hline Entire pregnancy & 8.7 & $-2.0,20.6$ & 0.11 & 3.1 & $-7.0,14.4$ & 0.56 \\
\hline
\end{tabular}

${ }^{a}$ The model is adjusted for maternal age, gestational age, smoking status, maternal education, alcohol consumption during pregnancy, season at conception, gender, and date of delivery.

${ }^{b}$ The effect size is calculated as a relative percent change for an IQR increment in $\mathrm{PM}_{10}$ or $\mathrm{PM}_{2.5}$ exposure $\left(\mu \mathrm{g} / \mathrm{m}^{3}\right)$ at the mother's residence during the different time windows. The IQR for the different time windows for $\mathrm{PM}_{10}$ and $\mathrm{PM}_{2.5}$ is given in Table 2 
excreted form of 8-OHdG is that this method gives a more direct measurement of oxidative damage occurring within mitochondria, and therefore, reflecting mitochondrial function. Repair of 8-OHdG lesions from the mitochondrial genome ensures a steady-state level of oxidative stress within the mitochondrion [8]. However, during long periods of PM-induced ROS exposure, 8-OHdG levels may accumulate in the body or tissue of both the mother and foetus and, therefore, oxidative mtDNA damage may be more extensive and persistent compared to nuclear DNA damage [30]. This accumulation over a long period of time could explain the association between 8-OHdG levels and $\mathrm{PM}_{10}$ exposure over the entire pregnancy. The strict maternal inheritance of mtDNA could imply that increased oxidative stress levels and mtDNA mutations present within mitochondria of the mother, predefine oxidative mtDNA damage levels within the foetus. Our findings showed that the association between maternal particulate air pollution and newborn mtDNA damage was most significantly associated with first and second trimester exposure windows, pointing to predefined mtDNA oxidative damage in susceptible windows of exposure during pregnancy. In contrast, the inverse trend we observed in trimester 3 could mean that the foetus is somewhat protected from maternal-derived ROS or might be the result of an early decrease in the number of mitochondria due to mitophagy [31] with less endogenous ROS formation. Early and mid-pregnancy exposure windows are critical for adverse newborn health outcomes, including preterm birth [32] and increased risk of gestational diabetes mellitus [33]. Unfortunately, we did find an association between gestational PM exposure and adverse pregnancy outcomes such as birth weight or small for gestational age.

However, our findings showed that mtDNA content, a measure of altered mitochondrial function, was associated with 8-OHdG levels in both maternal and cord blood [11, 34]. Exposure to PM-induced ROS is likely to cause oxidative mtDNA damage and subsequent mutations of mtDNA, leading to mitochondrial heteroplasmy or mixed mitochondrial populations $[9,35]$. If accumulation of 8-OHdG and somatic mtDNA mutations exceed a critical threshold, they can cause a biochemical defect in the mitochondrial respiratory chain and could result in a progressive decline of mitochondrial function $[10,34,36]$. Previously, we have shown that $\mathrm{PM}_{2.5}$ exposure during pregnancy affects global DNA methylation levels in placental tissue [37], and we found subtle differences in methylation levels of specific regions in the mitochondrial genome [31]. Besides metabolic disorders, the stochastic accumulation of mtDNA mutations encompasses the pathophysiological basis of disease processes including aging, neurodegenerative diseases, and cancer [38].
Oxidative modifications in mitochondria represent a potential link between adverse insults and altered foetal development. Increased oxidative stress levels in pregnancy, including levels of 8-OHdG, have been implicated in pregnancy complications and adverse outcomes such as gestational diabetes mellitus [39] and preeclampsia [40]. In our study, we did not observe an association between pregnancy outcomes such as birth weight or small for gestational age and 8-OHdG levels in maternal or cord blood. Nevertheless, the mitochondrial oxidative DNA damagemediated health effects of PM exposure need to be further elucidated.

The present study must be interpreted within the context of its limitations and strengths. We measured 8OHdG in mtDNA in mothers at the end of their pregnancy which consequently impairs the ability to investigate changes in 8 -OHdG in mitochondrial DNA during the entire pregnancy. However, a strength is that mitochondria capture long-term oxidative stress accumulation, and having samples of mother-newborn pairs, we were able to explore both effects on the mother and foetus. Although our results were consistent after multiple adjustments, we cannot exclude the possibility of residual confounding by some unknown factor that is associated with both 8-OHdG levels and ambient air pollution. Our findings were not influenced by other factors that possibly could alter the association between PM exposure and 8-OHdG levels or mtDNA damage such as smoking and use of assisted reproductive technology.

Prenatal exposure to $\mathrm{PM}_{10}$ in Flanders (Belgium), which is on average $21.4 \mu \mathrm{g} / \mathrm{m}^{3}$ in the mothernewborns pairs of our cohort, is associated with elevated mitochondrial oxidative stress, reflected by increased 8-OHdG levels in the mother and foetus. Our findings are generalisable as our study population is representative for the gestational segment of the population at large. Although our concentrations might be relatively high for affluent Western societies, the levels are low compared to other parts of the world e.g. in Lahore (Pakistan) with average $\mathrm{PM}_{10}$ concentrations above $700 \mu \mathrm{g} / \mathrm{m}^{3}$ and average $\mathrm{PM}_{2.5}$ concentrations above $180 \mu \mathrm{g} / \mathrm{m}^{3}$ [41].

\section{Conclusions}

We demonstrated that mitochondrial oxidative DNA damage in both newborns and their mothers was associated with particulate air pollution exposure during pregnancy. Future molecular epidemiological studies in newborns are required to clarify the impact of mitochondrial oxidative DNA damage on newborn's and children's health. 


\section{Additional file}

Additional file 1: Table S1. Mitochondrial and nuclear primer sequence information based upon Assembly GRCh37/hg19 of the UCSC genome browser for mtDNA content measurement. Table S2. Estimated change of mitochondrial 8-OHdG in maternal blood associated with $\mathrm{PM}_{10}$ and $\mathrm{PM}_{2.5}$ exposure during pregnancy while excluding women who continued smoking during pregnancy $(n=193)$. Table S3. Estimated change of mitochondrial 8-OHdG in cord blood associated with $\mathrm{PM}_{10}$ and $\mathrm{PM}_{2.5}$ exposure during pregnancy while excluding women who continued smoking during pregnancy $(n=246)$. Table S4. PM exposure, $8-\mathrm{OHdG}$ levels and pregnancy outcomes. (DOCX $24 \mathrm{~kb}$ )

\section{Abbreviations}

8-OHdG: 8-hydroxy-2'-deoxyguanosine; Cl: confidence interval; Ct: threshold cycles; hOGG1: human oxoguanine glycosylase 1; mtDNA: mitochondrial DNA; nDNA: nuclear DNA; PM: particulate matter; $\mathrm{PM}_{2.5}$ : particles with a diameter smaller than $2.5 \mu \mathrm{m}$; $\mathrm{PM}_{10}$ : particles with a diameter smaller than $10 \mu \mathrm{m}$; qPCR: quantitative real-time polymerase chain reaction; ROS: reactive oxygen species.

\section{Competing interests}

The authors declare they have no financial neither non-financial competing interests.

\section{Authors' contributions}

TSN coordinates the ENVIRONAGE birth cohort. LG, MH and VB measured mitochondrial 8-hydroxy-2'-deoxyguanosine. BGJ gave guidance to the field workers and the quality control of the database. BGJ and LG did the statistical analysis with guidance provided by TSN. BGJ developed the exposure matrixes with input from WL and CV. LG, BGJ and TSN wrote the first draft of the manuscript. All authors read and approved the final manuscript.

\section{Acknowledgements}

The authors thank the participating women and neonates, as well as the staff of the maternity ward, midwives, and the staff of the clinical laboratory of East-Limburg Hospital in Genk. The ENVIRONAGE birth cohort is supported by the European Research Council (ERC-2012-StG.310898), by the Flemish Scientific Fund (FWO, N1516112 / G.0.873.11.N.10) and the Bijzonder Onderzoeksfonds (BOF) of Hasselt University. Prof. Bollati and Mirjam Hoxha received support from the EU Programme "Ideas" (ERC-2011-StG 282413 to V. Bollati).

\section{Author details}

${ }^{1}$ EPIGET-Epidemiology, Epigenetics and Toxicology Lab-Department of Clinical Sciences and Community Health, Università degli Studi di Milano, Milan, Italy. ${ }^{2}$ Centre for Environmental Sciences, Hasselt University, Hasselt, Belgium. ${ }^{3}$ Belgian Interregional Environment Agency, Brussels, Belgium. ${ }^{4}$ Flemish Institute for Technological Research (VITO), Mol, Belgium ${ }^{5}$ Department of Public Health \& Primary Care, Occupational and Environmental Medicine, Leuven University, Leuven, Belgium.

\section{Received: 11 August 2015 Accepted: 10 January 2016}

\section{Published online: 20 January 2016}

\section{References}

1. Mazzoli-Rocha F, Fernandes S, Einicker-Lamas M, Zin WA. Roles of oxidative stress in signaling and inflammation induced by particulate matter. Cell Biol Toxicol. 2010;26(5):481-98.

2. Li N, Xia T, Nel AE. The role of oxidative stress in ambient particulate matterinduced lung diseases and its implications in the toxicity of engineered nanoparticles. Free Radic Biol Med. 2008;44(9):1689-99.

3. Grahame T, Schlesinger R. Oxidative stress-induced telomeric erosion as a mechanism underlying airborne particulate matter-related cardiovascular disease. Part Fibre Toxicol. 2012;9(1):21.

4. Nel A, Xia T, Madler L, Li N. Toxic potential of materials at the nanolevel. Science (New York, NY). 2006;311(5761):622-7.

5. Fialová L, Malbohan I, Kalousová M, Soukupová J, Krofta L, Štípek S, et al Oxidative stress and inflammation in pregnancy. Scand J Clin Lab Invest. 2006;66(2):121-8
6. Lee HC, Wei YH. Mitochondrial role in life and death of the cell. J Biomed Sci. 2000;7(1):2-15

7. Cheng KC, Cahill DS, Kasai H, Nishimura S, Loeb LA. 8-Hydroxyguanine, an abundant form of oxidative DNA damage, causes G-T and A-C substitutions. J Biol Chem. 1992;267(1):166-72.

8. de Souza-Pinto NC, Eide L, Hogue BA, Thybo T, Stevnsner T, Seeberg E, et al. Repair of 8-oxodeoxyguanosine lesions in mitochondrial dna depends on the oxoguanine dna glycosylase (OGG1) gene and 8-oxoguanine accumulates in the mitochondrial dna of OGG1-defective mice. Cancer Res. 2001;61(14):5378-81.

9. Payne BA, Wilson IJ, Yu-Wai-Man P, Coxhead J, Deehan D, Horvath R, et al Universal heteroplasmy of human mitochondrial DNA. Hum Mol Genet. 2013;22(2):384-90.

10. Kakimoto M, Inoguchi T, Sonta T, Yu HY, Imamura M, Etoh T, et al. Accumulation of 8-hydroxy-2'-deoxyguanosine and mitochondrial DNA deletion in kidney of diabetic rats. Diabetes. 2002;51(5):1588-95.

11. Lin CS, Wang LS, Tsai CM, Wei YH. Low copy number and low oxidative damage of mitochondrial DNA are associated with tumor progression in lung cancer tissues after neoadjuvant chemotherapy. Interact Cardiovasc Thorac Surg. 2008;7(6):954-8.

12. Vattanasit U, Navasumrit $P$, Khadka MB, Kanitwithayanun J, Promvijit J, Autrup $\mathrm{H}$, et al. Oxidative DNA damage and inflammatory responses in cultured human cells and in humans exposed to traffic-related particles. Int J Hyg Environ Health. 2013;217(1):23-33.

13. Sorensen M, Autrup $H$, Hertel $O$, Wallin H, Knudsen LE, Loft S. Personal exposure to PM2.5 and biomarkers of DNA damage. Cancer Epidemiol Biomarkers Prev. 2003;12(3):191-6.

14. Huang W, Wang G, Lu SE, Kipen H, Wang Y, Hu M, et al. Inflammatory and oxidative stress responses of healthy young adults to changes in air quality during the Beijing Olympics. Am J Respir Crit Care Med. 2012;186(11):1150-9.

15. Ren C, Fang S, Wright RO, Suh H, Schwartz J. Urinary 8-hydroxy-2'deoxyguanosine as a biomarker of oxidative DNA damage induced by ambient pollution in the Normative Aging Study. Occup Environ Med. 2011; 68(8):562-9.

16. Svecova V, Rossner Jr P, Dostal M, Topinka J, Solansky I, Sram RJ. Urinary 8-oxodeoxyguanosine levels in children exposed to air pollutants. Mutat Res. 2009;662(1-2):37-43.

17. Janssen BG, Munters E, Pieters N, Smeets K, Cox B, Cuypers A, et al. Placenta mitochondrial DNA content and particulate air pollution during in utero life. Environ Health Perspect. 2012;120(9):1346-52.

18. Janssen S, Dumont G, Fierens F, Mensink C. Spatial interpolation of air pollution measurements using CORINE land cover data. Atmos Environ. 2008;42(20):4884-903.

19. Lefebvre W, Degrawe B, Beckx C, Vanhulsel M, Kochan B, Bellemans T, et al. Presentation and evaluation of an integrated model chain to respond to traffic- and health-related policy questions. Environ Model Softw. 2013;40: 160-70.

20. Lefebvre W, Vercauteren J, Schrooten L, Janssen S, Degraeuwe B, Maenhaut W, et al. Validation of the MIMOSA-AURORA-IFDM model chain for policy support: modeling concentrations of elemental carbon in Flanders. Atmos Environ. 2011:45(37):6705-13.

21. Bollati V, Marinelli B, Apostoli P, Bonzini M, Nordio F, Hoxha M, et al. Exposure to metal-rich particulate matter modifies the expression of candidate microRNAs in peripheral blood leukocytes. Environ Health Perspect. 2010;1 18(6):763-8.

22. Hellemans J, Mortier G, De Paepe A, Speleman F, Vandesompele J. qBase relative quantification framework and software for management and automated analysis of real-time quantitative PCR data. Genome Biol. 2007; 8(2):R19.

23. Kim JY, Mukherjee S, Ngo LC, Christiani DC. Urinary 8-hydroxy-2'deoxyguanosine as a biomarker of oxidative DNA damage in workers exposed to fine particulates. Environ Health Perspect. 2004;112(6):666-71.

24. Chuang KJ, Chan CC, Su TC, Lee CT, Tang CS. The effect of urban air pollution on inflammation, oxidative stress, coagulation, and autonomic dysfunction in young adults. Am J Respir Crit Care Med. 2007;176(4):370-6.

25. Sauvain JJ, Setyan A, Wild P, Tacchini P, Lagger G, Storti F, et al. Biomarkers of oxidative stress and its association with the urinary reducing capacity in bus maintenance workers. J Occup Med Toxicol. 2011;6(1):18.

26. Prieme H, Loft S, Klarlund M, Gronbaek K, Tonnesen P, Poulsen HE. Effect of smoking cessation on oxidative DNA modification estimated by 8-0xo-7,8dihydro-2'-deoxyguanosine excretion. Carcinogenesis. 1998;19(2):347-51. 
27. Loft S, Vistisen K, Ewertz M, Tjonneland A, Overvad K, Poulsen HE. Oxidative DNA damage estimated by 8-hydroxydeoxyguanosine excretion in humans: influence of smoking, gender and body mass index. Carcinogenesis. 1992; 13(12):2241-7.

28. Loft S, Poulsen HE, Vistisen $K$, Knudsen LE. Increased urinary excretion of 8-oxo-2'-deoxyguanosine, a biomarker of oxidative DNA damage, in urban bus drivers. Mutat Res. 1999;441(1):11-9.

29. Yao $\mathrm{QH}$, Mei $\mathrm{SR}$, Weng $\mathrm{QF}$, Zhang $\mathrm{PD}$, Yang $\mathrm{Q}$, Wu CY, et al. Determination of urinary oxidative DNA damage marker 8-hydroxy-2'-deoxyguanosine and the association with cigarette smoking. Talanta. 2004;63(3):617-23.

30. Yakes FM, Van Houten B. Mitochondrial DNA damage is more extensive and persists longer than nuclear DNA damage in human cells following oxidative stress. Proc Natl Acad Sci U S A. 1997;94(2):514-9.

31. Janssen BG, Byun H-M, Gyselaers W, Lefebvre W, Baccarelli AA, Nawrot TS. Placental mitochondrial methylation and exposure to airborne particulate matter in the early life environment: An ENVIRONAGE birth cohort study. Epigenetics. 2015;10(6):536-44.

32. Chang HH, Warren JL, Darrow LA, Reich BJ, Waller LA. Assessment of critical exposure and outcome windows in time-to-event analysis with application to air pollution and preterm birth study. Biostatistics. 2015;16(3):509-521.

33. Robledo CA, Mendola P, Yeung E, Mannisto T, Sundaram R, Liu D, et al. Preconception and early pregnancy air pollution exposures and risk of gestational diabetes mellitus. Environ Res. 2015;137:316-22.

34. Torres-Gonzalez M, Gawlowski T, Kocalis H, Scott BT, Dillmann WH. Mitochondrial 8-oxoguanine glycosylase decreases mitochondrial fragmentation and improves mitochondrial function in $\mathrm{H} 9 \mathrm{C} 2$ cells under oxidative stress conditions. Am J Physiol Cell Physiol. 2014;306:C221-9.

35. Wallace DC. Mitochondrial DNA, mutations in disease and aging. Environ Mol Mutagen. 2010;51(5):440-50.

36. Wallace DC, Chalkia D. Mitochondrial DNA genetics and the heteroplasmy conundrum in evolution and disease. Cold Spring Harb Perspect Biol. 2013; 5(11):a021220.

37. Janssen BG, Godderis L, Pieters N, Poels K, Kicinski M, Cuypers A, et al. Placental DNA hypomethylation in association with particulate air pollution in early life. Part Fibre Toxicol. 2013;10:22.

38. Schon EA, DiMauro S, Hirano M. Human mitochondrial DNA: roles of inherited and somatic mutations. Nat Rev Genet. 2012;13(12):878-90.

39. Qiu C, Hevner K, Abetew D, Enquobahrie DA, Williams MA. Oxidative DNA damage in early pregnancy and risk of gestational diabetes mellitus: a pilot study. Clin Biochem. 2011;44(10-11):804-8.

40. Scholl TO, Stein TP. Oxidant damage to DNA and pregnancy outcome. J Matern Fetal Med. 2001;10(3):182-5.

41. Sughis M, Nawrot T, Ihsan-ul-Haque S, Amjad A, Nemery B. Blood pressure and particulate air pollution in schoolchildren of Lahore, Pakistan. BMC Public Health. 2012;12(1):378.

\section{Submit your next manuscript to BioMed Central and we will help you at every step:}

- We accept pre-submission inquiries

- Our selector tool helps you to find the most relevant journal

- We provide round the clock customer support

- Convenient online submission

- Thorough peer review

- Inclusion in PubMed and all major indexing services

- Maximum visibility for your research

Submit your manuscript at www.biomedcentral.com/submit

) Biomed Central 